\title{
Relationship between Bile Acid Transplacental Gradients and Transport across the Fetal-Facing Plasma Membrane of the Human Trophoblast
}

\author{
M. J. MONTE, T. RODRIGUEZ-BRAVO, R. I. R. MACIAS, P. BRAVO, ${ }^{1}$ M. Y. EL-MIR, \\ M. A. SERRANO, A. LOPEZ-SALVA, AND J. J. G. MARIN \\ Departments of Physiology and Pharmacology [M.J.M., R.I.R.M., P.B., M.Y.E.-M., J.J.G.M.] and \\ Biochemistry and Molecular Biology [M.A.S.], University of Salamanca, and Department of Gynecology \\ and Obstetrics, Virgen de la Vega Hospital [T.R.-B., A.L.-S.], Salamanca, Spain
}

\begin{abstract}
Bile acids and bilirubin are synthesized by the fetal liver very early on during intrauterine life. The main fate of these compounds is to be transferred to the mother. This excretory role of the placenta is primarily determined by the ability of the trophoblast to transport them, which is believed to occur mainly by carrier-mediated processes. The aim of this study was to investigate the role of the cholephilic organic anion exchanger located in the fetal-facing plasma membrane of the human trophoblast in placental "biliary-like" function. No relationship between the magnitude of transplacental gradients for total bile acids and bilirubin was found. However, transport studies, which were carried out by using purified plasma membrane vesicles derived

transplacental gradient for bile acid species was not correlated with their hydrophobic/hydrophilic balance, as would be expected if diffusion across the lipidic structures of the placental barrier would be the major pathway for the flux of bile acid across this organ. In summary, these results indicate that carriers located in the basal plasma membrane may play an important role in the control of the qualitative and quantitative fetalmaternal bile acid exchange. Moreover, they suggest that although both bile acids and bilirubin may share this pathway for access to the trophoblast, other additional mechanisms are probably responsible in part for the control of the magnitude of their transplacental gradients. (Pediatr Res 38: 156-163, 1995)
\end{abstract} from the fetal-facing pole of the human trophoblast, revealed that $\left[{ }^{14} \mathrm{C}\right]$ taurocholate transport was affected by both another bile acid (taurochenodeoxycholic acid) and a non-bile acid cholephilic organic anion (bromosulfophthalein). On plotting the ability of different major bile acid species to inhibit radiolabeled taurocholate uptake by these vesicles versus their concentrations in fetal serum or the magnitude of their transplacental gradients, inverse relationships were found. Lower fetal serum concentrations and transplacental gradients were found for bile acid species with higher abilities to affect this transport and presumably to interact with the carrier. By contrast, the magnitude of the

Very early on in gestational life, the fetal liver is able to efficiently synthesize bile acids. The main fate of these molecules is to be transferred to the maternal blood where the concentrations are markedly lower than those measured in the fetal blood (1). The magnitude of this difference is established by a dynamic equilibrium involving the rate of bile acid synthesis by both fetal and maternal livers, together with the

Reccived Junc 30, 1994; accepted February 20, 1995

Correspondence: Jose Juan Garcia Marin, Departamento de Fisiologia y Farmacologia. Campus Miguel de Unamuno, E.1.D. S-(09, 37007-Salamanca, Spain.

Supported in part by the Fondo de Investigaciones Sanitarias de la Seguridad Socia (93/0419).

'P.B. was a Research Fellow of the Ministerio de Educación y Ciencia, Spain.

\section{Abbreviations}

bTPM, trophoblastic basal plasma membrane

Hepes, $N$-2-hydroxyethylpiperazine- $N^{\prime}$-2-ethanesulfonic acid BSP, bromosulfophthalein

TC, taurocholic acid $(3 \alpha, 7 \alpha, 12 \alpha$-trihydroxy-5 $\beta$-cholestanoic acid)

CDC, chenodeoxycholic acid

TCDC, taurochenodeoxycholic acid $(3 \alpha, 7 \alpha$-dihydroxy-5 $\beta$ cholestanoic acid)

output of these compounds from both compartments. Escape from the fetal compartment into the maternal blood mainly occurs by placental transfer, although small additional renal excretion into the amniotic fluid does also exist. If the enterohepatic circulation is present in the fetus, its magnitude and hence bile acids loss into the meconium are assumed to be negligible (2). By contrast, in healthy pregnant women, the liver is able to handle the additional supply of bile acids by increasing their secretion into bile. Therefore, fecal excretion is probably the main way for the elimination of bile acids from the mother-fetus tandem. However, a smaller contribution of the maternal kidney in eliminating bile acids, mainly sulfated and glucuronated, should also be considered. A fetal-maternal 
bile acid steady-state is established with the existence of a greater concentration of these compounds in the fetal blood as compared with the maternal one. An important role in controlling the magnitude of this transplacental gradient is probably played by the ability and selectivity of the mechanisms involved in bile acid transfer across the trophoblast (2). Owing to the low permeability of lipid bilayers for anionic bile acid molecules (3), it is believed that transport processes more efficient than simple diffusion must underlie this function of the trophoblast. The existence of carrier systems for bile acids both in the basal (fetal-facing) and the brush-border (maternalfacing) membranes of this tissue has been reported previously (4-7). The substrate specificity of these carriers (8) may account in part for the selective exchange of bile acid species between the fetal and the maternal bile acid pools.

Bile acids are not the only cholephilic compounds that the fetus must export to the mother. Bilirubin, which is produced by the fetus in considerable amounts every day and which is potentially toxic, specially for certain fetal tissues (namely, the nervous system), is transferred by the placenta as part of what can be called the "biliary-like" function of this organ. In the hepatocyte, no relevant interaction between major bile acid species and bilirubin at carrier protein level exists (9). However, in the human trophoblast, the available experimental evidence suggests that several cholephilic organic anions may interact with the bile acid carrier located in the basal plasma membrane (10). Thus, an interesting question arises as to how this excretory function of the human placenta differs from that of the adult liver.

Quantitative assessment of the functional efficiency of the placenta yields important information for obstetricians who have to investigate the overall well-being of the fetus in terms of nutritional supply and equilibrated placental and fetal growth. Until now, the most generalized parameters have been restricted to those provided by morphologic observations, such as the extent of infarctions or intervillous hematoma of the placental parenchyma, together with certain measurements. These include the weight and size of the placenta, the relationship between fetal weight at birth and gestational time, and the placental/fetal weight ratio. However, although such data are readily obtained, the information provided is very reduced. Attempts have been made to increase the accuracy of morphologic studies by developing computer-assisted measurement programs capable of semiautomatic histometric investigation of the human placenta $(11,12)$. Nevertheless, the development of new and readily available functional measurements would be desirable. In this sense, it can be hypothesized that, if transplacental gradients of bile acids and/or bilirubin are directly affected by impairment in the excretory function of the placenta, determination of fetal and maternal serum concentrations for these compounds may provide useful diagnostic information to evaluate the health of the placenta in pregnancies unaccompanied by fetal or maternal liver disease.

\section{METHODS}

Chemicals. Cholic acid, glycocholic acid, TC, CDC, glycochenodeoxycholic acid, TCDC, ursodeoxycholic acid, taurour- sodeoxycholic acid, deoxycholic acid, glycodeoxycholic acid, taurodeoxycholic acid, BSA, dihydroalprenolol, L-alanine, BSP, Tris, $3 \alpha$-hydroxysteroid dehydrogenase, diaphorase, resazurin, and the substrates and enzymes necessary for activity determinations were purchased from Sigma Chemical Co. (St. Louis, MO). Glycoursodeoxycholic acid was from Calbiochem (San Diego, CA). All bile acids were more than $95 \%$ pure by thin-layer chromatography. Hepes was purchased from Boehringer (Mannheim $\mathrm{GmbH}$, Germany). $\mathrm{L}-\left[{ }^{14} \mathrm{C}\right]$ alanine (specific radioactivity, $160 \mathrm{mCi} / \mathrm{mmol}$ ) was obtained from Center d'Etudes Nucleaires de Saclay (CEA, Gif-sur-Yvette, France). Both $\left[{ }^{3} \mathrm{H}\right]$ dihydroalprenolol and $\left[{ }^{14} \mathrm{C}\right]$ taurocholate (specific radioactivity, $50 \mathrm{Ci} / \mathrm{mmol}$ and $46.7 \mathrm{mCi} / \mathrm{mmol}$, respectively) were obtained from DuPont NEN (Itisa, Madrid, Spain). All other chemicals were from Merck (Darmstadt, Germany) or Sigma Chemical Co.-Aldrich Quimica S.A. (Madrid, Spain).

Maternal and fetal serum samples. To investigate the magnitude of the transplacental gradients for several compounds, including some typical biliary excreted substances, peripheral blood samples from 20 healthy pregnant women were collected at term, a few minutes before delivery. Twenty paired fetal blood samples were also obtained from the umbilical cord at birth. Selection of the mothers entering the study was carried out from among patients with $\approx 40 \mathrm{wk}$ long of uncomplicated pregnancy who had no major disease. The absence of hepatitis, cirrhosis, or any other hepatic or gastrointestinal disease was investigated at the time of selection. Samples from mothers showing antigenicity for toxoplasmosis and AIDS were also discarded. The study was approved by the Investigational Review Board of the University of Salamanca, Salamanca, Spain, and permission was obtained from the mothers before samples were collected.

Preparation of human placental basal plasma membrane vesicles. $\mathrm{BTPM}$ vesicles were purified from normal human placentas obtained at term from the above-mentioned pregnancies after uncomplicated vaginal delivery at the Gynecology and Obstetrics Department of the "Virgen de la Vega" Hospital, Salamanca, Spain. The bTPM vesicles were prepared by a modification of the method of Kelley et al. (13) as described elsewhere (4). The purity and contamination of the preparations were assayed as indicated in a previous report (4) by dihydroalprenolol binding (14) as a marker for bTPM; alkaline phosphatase activity (EC 3.1.3.1) (15) as a marker for apical plasma membrane; $\mathfrak{L}(+)$-tartrate-sensitive acid phosphatase (EC 3.1.3.2) (16) as a marker for lysosomal membrane; glucose 6-phosphatase (EC 3.1.3.9) (17) as a marker for microsomal membrane; and succinic dehydrogenase (EC 1.3.99.1) (18) as a marker for mitochondrial membrane. The results for basal membrane enrichment and contamination by apical membrane are given in Table 1. Both these results and those concerning contamination by intracellular membranes (data not shown) were similar to the parameters described elsewhere (4). The integrity and orientation of the bTPM vesicles obtained by this method have been reported previously (19). Vesicle preparations were stored in buffer A $(250 \mathrm{mM}$ sucrose, $100 \mathrm{mM}$ $\mathrm{KNO}_{3}, 10 \mathrm{mM} \mathrm{MgCl}_{2}, 0.2 \mathrm{mM} \mathrm{CaCl}, 10 \mathrm{mM}$ Hepes/Tris, $\mathrm{pH}$ 7.40 ) at $-80^{\circ} \mathrm{C}$ until used. Before carrying out the experiments the vesicles were first thawed and then diluted with buffer $A$ to 
Table 1. Purity of bTPM vesicles

\begin{tabular}{lccc}
\hline & Homogenate & bTPM & Enrichment \\
\hline $\begin{array}{l}\text { Dihydroalprenelol (DHAP) } \\
\text { binding (pmol DHAP/mg } \\
\text { protein) }\end{array}$ & $0.012 \pm 0.002$ & $0.35 \pm 0.09$ & 29.2 \\
$\begin{array}{l}\text { Alkaline phosphatase } \\
(\mu \mathrm{mol} / \mathrm{h} / \mathrm{mg} \text { protein) }\end{array}$ & $6.8 \pm 1.6$ & $30.1 \pm 8.3$ & 4.4 \\
\hline
\end{tabular}

Enrichment was calculated from the ratio of marker enzyme activity in the membrane vesicle preparations to activity in the homogenates. Results are means $\pm \mathrm{SEM}$ from four different vesicle preparations. Assays were carried out in triplicate for each preparation.

approximately $5 \mathrm{mg}$ protein/mL for uptake experiments and 10 $\mathrm{mg} / \mathrm{mL}$ for efflux experiments. Membranes were vesiculated by six passages through a 25 -gauge needle. Protein was determined by a modification of the method of Lowry (20), with BSA as a standard.

Transport studies. To carry out transport studies, TC retention by bTPM vesicles was measured by a rapid filtration technique (21). Experiments were initiated by adding $80 \mu \mathrm{L}$ of incubation buffer to $20 \mu \mathrm{L}$ of membrane vesicles prepared in the desired loading medium (approximately $5 \mu \mathrm{g}$ protein $/ \mu \mathrm{L}$ ). The compositions and conditions of different incubation and loading buffers are indicated in the figure legends. Based on previous studies (8), experiments were performed at $37^{\circ} \mathrm{C}$, using incubation times (30 s) short enough to fulfill the requirement of measuring linear transport, i.e. initial velocity. Incubation was terminated by the addition of $4 \mathrm{~mL}$ of ice-cold stop solution $\left(250 \mathrm{mM} \mathrm{KCl}, 25 \mathrm{mM} \mathrm{MgSO}_{4}, 10 \mathrm{mM}\right.$ Hepes/ Tris, $\mathrm{pH}$ 7.40) and immediate filtration through $0.65 \mu \mathrm{m}$ Millipore cellulose-nitrate filters (Millipore, Madrid, Spain) prewashed with stop solution. The incubation test tubes and subsequently the filters were rinsed once again with the same stop solution and then three additional times with a similar stop solution containing $0.1 \mathrm{mM}$ unlabeled bile acid. This procedure, selected on the basis of preliminary studies (4), reduces the retention of radioactivity by the filters (blank). Additional washes do not further reduce the amount of radioactivity retained by filter + vesicles. Pretreatment of the vesicles with $0.5 \%$ Triton $\mathrm{X}-100$ almost abolishes radioactivity retention. Therefore, the radioactivity measured in the present study can be assumed to be mainly due to intravesicular TC. In uptake experiments, values were corrected for the radioactivity found on the filters when vesicles were added once the ice-cold stop solution had already been mixed with the incubation medium. Typically, $5 \times 10^{4} \mathrm{dpm}$ applied to the filters gave an average blank of less than $50 \mathrm{dpm}$. In the efflux experiments, total loaded radioactivity after $2 \mathrm{~h}\left(\mathrm{Q}_{0}\right)$ was measured by rapid filtration after adding $20 \mu \mathrm{L}$ of the vesicle suspension and 80 $\mu \mathrm{L}$ of the incubation medium directly to $4 \mathrm{~mL}$ of ice-cold stop solution. Net efflux was calculated by subtracting the actual value of radioactivity found at $30 \mathrm{~s}$ of incubation time $\left(\mathrm{Q}_{\mathrm{t}}\right)$ from the $\mathrm{Q}_{0}$ determined for each specific loaded vesicle preparation. Radioactivity on the filters was measured in a liquid scintillation spectrometer (LS-1800-Beckman, Beckman Instruments, Madrid, Spain) using the Ready Safe Scintillation Cocktail, also from Beckman, as scintillant. To perform efflux experiments, the vesicles were previously loaded with TC as follows: a double concentrated suspension of purified membrane preparation was diluted 1:1 with buffer A containing $2 \times$ C mM unlabeled TC plus approximately $5,000 \mathrm{dpm} / \mu \mathrm{L}$ $\left[{ }^{14} \mathrm{C}\right] \mathrm{TC}$, where $\mathrm{C}$ was the desired final concentration of TC plus $\left[{ }^{14} \mathrm{C}\right] \mathrm{TC}$. Membrane vesicles were incubated with the buffer containing labeled and unlabeled TC at $25^{\circ} \mathrm{C}$ for $2 \mathrm{~h}$ before use.

Analytical methods. Bile acids were obtained from serum samples by liquid-solid extraction (22). Serum samples were diluted $(1: 4, \mathrm{vol} / \mathrm{vol})$ with $0.4 \mathrm{M} \mathrm{NH}_{4} \mathrm{HCO}_{3}$ and heated to $64^{\circ} \mathrm{C}$ for $2 \mathrm{~h}$. Samples were centrifuged for $15 \mathrm{~min}$ at $5000 \times \mathrm{g}$. The resulting supernatants were heated again for $10 \mathrm{~min}$ and $\mathrm{ex}$ tracted using reverse phase octadecylsilane bonded silica cartridges (Sep-Pak, Waters-Millipore, Madrid, Spain). After washing the cartridges with water $(10 \mathrm{~mL})$, acetone $(3 \mathrm{~mL} 10 \%$ in water) and water $(10 \mathrm{~mL})$, bile acids were recovered with 4 $\mathrm{mL}$ of methanol. This solution was filtered using a "Sample Clarification Kit" (Waters-Millipore) and dried. To carry out total bile acid measurement and HPLC, the sample was redissolved with $200 \mu \mathrm{L}$ methanol. This procedure allows both an efficient elimination of serum components other than bile acids and also reconcentration of bile acids by about 20 -fold, which is required to perform subsequent analytical procedures. Total bile acid concentrations were measured by a sensitive method based on the stoichiometric conversion of $3 \alpha$-hydroxyl-bile acid into 3-keto-bile acid together with the generation of a fluorescent molecule of resorfin from one of resazurin by the sequential action of $3 \alpha$-hydroxysteroid dehydrogenase and diaphorase in the presence of $\mathrm{NAD}^{+}$as cofactor $(23,24)$. Serum bile acid species were separated by reversed phase HPLC analysis using a modification of the method of Rossi et al. (25) as previously described (26). In brief, HPLC was performed using a ODS Ultrasphere IP column $(5 \mu \mathrm{m}, 4.6 \mathrm{~mm}$ $\times 25 \mathrm{~cm}$, Beckman Instruments, Madrid, Spain) with a gradient pump module (model 126, Beckman) and a photo-diodearray detector (model 168, Beckman) set at $205 \mathrm{~nm}$. The system was controlled by an IBM computer (model 30286, IBM Corp., Portsmouth, UK) using System Gold software from Beckman. The column was equilibrated with solvent $\mathrm{A}$ (methanol:10 $\mathrm{mM} \mathrm{KH}_{2} \mathrm{PO}_{4}, 76: 24, \mathrm{pH} 5.45$ ), and eluted with a linear gradient from $50 \%$ water, $50 \%$ solvent $\mathrm{A}$ to $100 \%$ solvent A in $20 \mathrm{~min}$. This was kept in isocratic conditions for an additional 20 -min period, followed by a linear gradient from $100 \%$ solvent $A$ to $100 \%$ methanol in $50 \mathrm{~min}$. Throughout the chromatogram, the solvent rate was $1 \mathrm{~mL} / \mathrm{min}$. Reconstruction and quantification of the chromatographic separations were performed by fluorescence measurement obtained from enzymatic reaction, carried out as described above, in collected fractions ( $0.5 \mathrm{~min}$ each). Recovery values were $89 \pm 15 \%$ (SEM). Bile acid identification in this HPLC system was established by comparison with the elution times determined using commercial standards.

Determinations of other serum components were carried out in an automated system (Hitachi 717, Boehringer Mannheim, $\mathrm{GmbH}$, Germany) according to the adapted methods for total bilirubin (27), glucose (28), urea (29), cholesterol (30), high density lipoprotein-cholesterol (30), triglycerides (31), glutamic-oxaloacetic transaminase (EC 2.6.1.1) (32), glutamic- 
pyruvic transaminase (EC 2.6.1.2) (33), $\gamma$-glytamyl transferase (EC 2.3.2.2) (34), lactic acid dehydrogenase (EC 1.1.1.27) (35), and alkaline phosphatase (EC 3.1.3.1) (36).

Statistical analysis. Results are expressed as means \pm SEM. For calculating the statistical significance of differences, the paired $t$ test or the Bonferroni method of multiple-range testing was used, as appropriate. Regression lines were obtained by the least squares method. Statistical analysis was performed on a Macintosh LC-III computer (Apple Computer, Inc., Cupertino, CA) with programs supplied by Apple Computer, Inc.

\section{RESULTS}

To investigate the magnitude of the transplacental gradient for several compounds, including some substances typically excreted by the biliary system, 20 paired, i.e. maternal and fetal, blood samples were collected before and immediately after the delivery, respectively. Table 2 shows the values of routine laboratory analyses carried out by conventional techniques. The values found in the serum of these women were consistent with the healthy state of these pregnant women at term. Pregnancy accounts for the high level of alkaline phosphatase which, in this case, should not be associated with cholestasis, as indicated by the low levels of serum bilirubin. Other parameters included in Table 2 usually considered as indicators of liver function suggest the absence of liver impairment. High serum levels of cholesterol and triglycerides are in the range usually seen in the third trimester of normal pregnancies.

Measurements carried out on serum samples from these mothers and their fetuses indicated that both total bilirubin and total bile acid concentrations were higher in the fetus, i.e. a transplacental gradient in the fetal-maternal direction for these compounds does exist (Fig. 1). If we assume that the magnitude of transplacental gradients is inversely proportional to the capability of the compounds to cross the placental barrier, then it must be suggested that the placental transfer for bile acids must be more efficient than that for bilirubin. This rationale is consistent with the fact that easily crossing compounds such as

Table 2. Serum determinations in pregnant women at term

\begin{tabular}{|c|c|c|c|}
\hline & Units & Values & $\begin{array}{l}\text { Reference } \\
\text { range }^{a}\end{array}$ \\
\hline Alkaline phosphatase & $\mathrm{U} / \mathrm{L}$ & $308 \pm 20$ & $73-207$ \\
\hline$\gamma$-Glutamyltransferase & $\mathrm{U} / \mathrm{L}$ & $10.3 \pm 2.6$ & $7.0-38.0$ \\
\hline $\begin{array}{l}\text { Glutamic-oxaloacetic } \\
\text { transaminase }\end{array}$ & $\mathrm{U} / \mathrm{L}$ & $15.9 \pm 1.9$ & $5.0-25.0$ \\
\hline Glutamic-pyruvic transaminase & $\mathrm{U} / \mathrm{L}$ & $15.1 \pm 3.6$ & $5.0-29.0$ \\
\hline Lactic acid dehydrogenase & $U / L$ & $258 \pm 20$ & $160-320$ \\
\hline $\begin{array}{l}\text { High density lipoprotein- } \\
\text { cholesterol }\end{array}$ & $\mathrm{mg} / \mathrm{dL}$ & $53.1 \pm 2.7$ & $25.0-55.0$ \\
\hline Cholesterol & $\mathrm{mg} / \mathrm{dL}$ & $241 \pm 10$ & $100-220$ \\
\hline Triglycerides & $\mathrm{mg} / \mathrm{dL}$ & $210 \pm 15$ & $70-150$ \\
\hline Urea & $\mathrm{mg} / \mathrm{dL}$ & $22.8 \pm 1.2$ & $10.0-50.0$ \\
\hline Glucose & $\mathrm{mg} / \mathrm{dL}$ & $93 \pm 7$ & $65-110$ \\
\hline Total bilirubin & $\mathrm{mg} / \mathrm{dL}$ & $0.36 \pm 0.06$ & $0.20-1.50$ \\
\hline
\end{tabular}

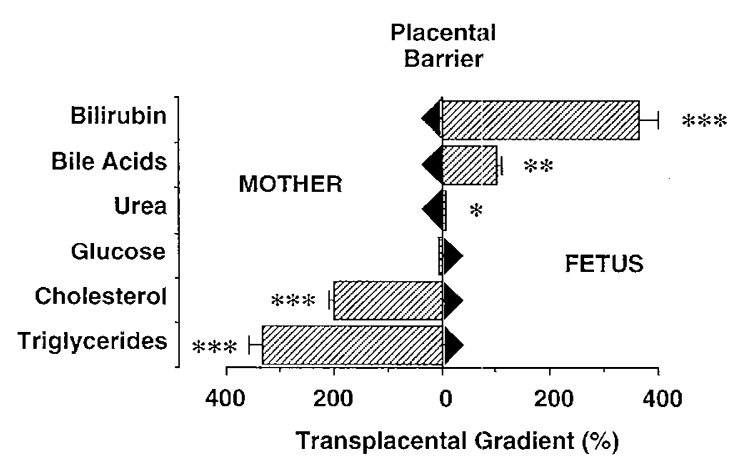

Figure 1. Transplacental gradients for total bile acids, total bilirubin, urea, glucose, cholesterol, and triglycerides. Values are means \pm SEM from data obtained by determining concentrations in paired serum samples collected at term from mothers and fetuses $(n=20)$ immediately before and after the delivery, respectively. ${ }^{*} p<0.05 ;{ }^{* *} p<0.01 ;{ }^{* *} p<0.001$ from comparison of maternal and fetal concentrations by a paired $t$ test.

urea and glucose were found to have transplacental gradients of very small magnitude (Fig. 1). However, this can be only partly true, because other factors in addition to placental transfer are involved in establishing serum fetal and maternal concentrations of these compounds. An important difference between the liver and the placenta with respect to the transport of lipophilic compounds is that bile acids and bilirubin are secreted into bile by the liver, as also occurs for cholesterol and phospholipids, whereas in the placenta the transfer of bile acids and bilirubin takes place in the opposite direction to that of the main flux for other lipidic compounds. The functional advantage of this difference is evident; the existence of a transplacental gradient for cholesterol and triglycerides (Fig. 1) provides the physical bases for the supply of these compounds from the maternal blood to the fetus and the placenta which use them mainly for their structural and hormonal requirements.

As far as bile acids and bilirubin are concerned, the first step in their transfer from the fetus to the mother is their transport across the basal plasma membrane of the trophoblast. At least for bile acids, a carrier-mediated system seems to be involved in this process (4). The system has been previously reported to behave as an anion exchanger $(10,19)$. In the current study, using highly enriched fetal-facing plasma membrane vesicles (Table 1) and radiolabeled TC, determinations of the rate of bile acid transport across this membrane were performed in the presence of other bile acid molecular species and a typical non-bile acid cholephilic organic anion, such as BSP.

As shown in Figure 2, TC efflux from previously loaded vesicles was strongly affected by the presence in the incubation medium of TCDC, a TC analog lacking the hydroxyl group at C12. The loading of the membrane vesicles with $300 \mu \mathrm{M}$ TCDC, in addition to $50 \mu \mathrm{M}$ TC, significantly reduced the magnitude of TC efflux from the vesicles. This is not consistent with vesicle damage, because in this case an increased loss of vesicle content would be expected instead of greater TC retention in the presence of TCDC $(10,19)$. By contrast, TC efflux from preloaded bTPM vesicles was increased when $300 \mu \mathrm{M}$ TCDC was placed in the extravesicular medium. This TCDCinduced trans-stimulating effect was not seen when the efflux of a non-bile acid compound, such as $\mathrm{L}-\left[{ }^{14} \mathrm{C}\right]$ alanine, was 


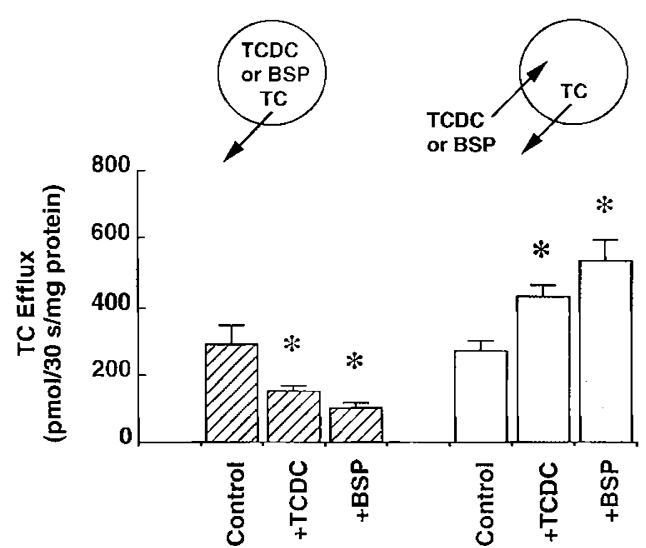

Figure 2. Cis-inhibition and trans-stimulation of $50 \mu \mathrm{M}\left[{ }^{14} \mathrm{C}\right]$ taurocholate efflux from preloaded basal plasma membranc vesicles in the presence of 300 $\mu \mathrm{M}$ TCDC or $300 \mu \mathrm{M}$ BSP in the intravesicular (striped bars) or the extravesicular media (gray bars), respectively. Control experiments in the absence of TCDC or BSP were included in cach set of experiments. In both types of experiments the rest of the intravesicular and extravesicular medium components were $250 \mathrm{mM}$ sucrose, $100 \mathrm{mM} \mathrm{KNO}_{3}, 10 \mathrm{mM} \mathrm{MgCl}_{2}, 0.2 \mathrm{mM}$ $\mathrm{CaCl}_{2}, 10 \mathrm{mM}$ Hepes/Tris, pH 7.40. Experiments were carried out in triplicate on five different placental plasma membrane vesicle preparations. Valucs are means \pm SEM. ${ }^{*} p<0.05$ compared with controls by the Bonferroni method of multiple-range testing.

investigated. L-Alanine efflux, from vesicles that were preloaded by incubation for $2 \mathrm{~h}$ at $37^{\circ} \mathrm{C}$ with $100 \mu \mathrm{M}$ L-alanine, was found to be not significantly different, as compared measurements carried out in the absence $(135 \pm 18 \mathrm{pmol} / 60 \mathrm{~s} / \mathrm{mg}$ protein; $n=3)$ and in the presence $(140 \pm 21 \mathrm{pmol} / 60 \mathrm{~s} / \mathrm{mg}$ protein; $n=3$ ) of $300 \mu \mathrm{M}$ extravesicular TCDC. Additionally, experiments where TCDC was replaced by the cholephilic organic anion BSP were carried out. BSP is usually preferred to bilirubin because of its higher stability and easier handling. Figure 2 shows that, as was found for TCDC, BSP induced a significant $c i s$-inhibition when located on the same side of the membrane as TC, and induced trans-stimulation when it was present on the opposite side to TC. These findings confirm and extend previous reports on the nature of this carrier as an anion exchanger system $(10,19)$.

These results support the interest in investigating the existence of any functional relationship between bile acid and bilirubin as far as their transfer across the placenta is concerned. Measurement of the concentrations of these two compounds in fetal and maternal blood revealed no significant correlation between the magnitude of their transplacental gradient (data not shown). Because fetal serum concentrations of these compounds are the result of several mechanisms, including both the rate of fetal and maternal production and the efficiency and vectoriality of placental transfer, these results may suggest either a different pathway as the major route for bile acid and bilirubin transport across the trophoblast and/or a markedly different rate of fetal plus maternal synthesis for both types of compounds. No relationship between the level of bile acids in fetal blood and the concentration of other structurally related or, by contrast, very different lipidic compounds, such as cholesterol and triglycerides, respectively, was found (data not shown).
Investigation of the relationship between the hydrophilic/ hydrophobic balance of bile acid species and their accumulation in fetal blood supports the concept that simple diffusion across the plasma membranes of the trophoblast is not a major pathway in the placental transfer of these compounds, because if that would be the case, lower accumulation within the fetal compartment would be expected for more lipophilic bile acid species, which is not in agreement with our observations (Fig. 3).

The last set of experiments was performed to focus our investigation on the role of the basal plasma membrane of the human trophoblast in the selection of bile acid molecular species to be transported toward the mother. Because all the proper radiolabeled species are not available we performed the study according with the following approximation. If it is assumed that, in our experimental conditions, the ability to inhibit TC transport is an indirect indicative of the ability to interact with the bile acid carrier, and hence to be transported across this membrane, it can be expected that molecular species able to induce higher TC transport inhibition also cross this membrane more efficiently. Accordingly, their transplacental gradient would be also expected to be lower. In this regard, Figure 4 shows that an inverse correlation exists between bile acid-induced inhibition of TC transport across the fetal-facing membrane of the trophoblast and fetal serum concentrations for most of the major bile acid species. When comparison was made after taking into account maternal serum concentrations, i.e. considering transplacental gradients, as shown in Figure 5, it was found that bile acids with a higher ability to interact with the carrier were actually more concentrated in the mother than in the fetus, whereas molecular species with a poor ability to interact with the carrier remained accumulated in the fetal blood. Although nonlinear correlations

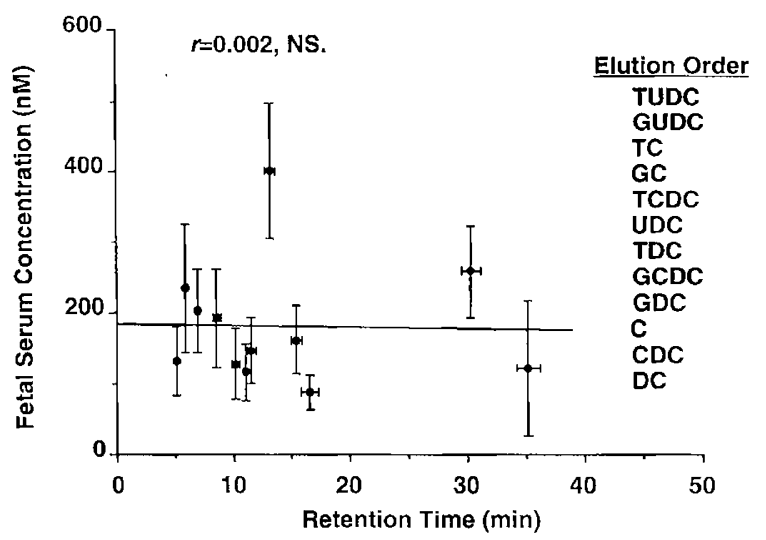

Figure 3. Relationship between fetal serum concentrations of bile acid species as measured by HPLC separation combined with enzymatic fluorescent quantification and their hydrophobic/hydrophilic balance as revealed by their retention time in reversed phase HPLC analysis using a ODS Ultrasphere IP column $(5 \mu \mathrm{m}, 4.6 \mathrm{~mm} \times 25 \mathrm{~cm})$ and a mixture $(76: 24)$ of methanol and 10 $\mathrm{mM} \mathrm{KH} \mathrm{KH}_{2} \mathrm{PO}_{4}, \mathrm{pH} 5.50$, as mobilc phase in an isocratic system at $1 \mathrm{~mL} / \mathrm{min}$. Values are means \pm SEM from data obtained by determining concentrations in fetal serum samples $(n=20)$ collected at term immediately after the delivery. NS, no significant correlation. TUDC, tauroursodeoxycholic acid; GUDC, glycoursodeoxycholic acid; GC, glycocholic acid; UDC, ursodeox ycholic acid; TDC, taurodeoxychoktc; GCDC, glycochenodeoxycholic acid; GDC, glycodeoxycholic acid; C, cholic acid; DC, deoxycholic acid. 


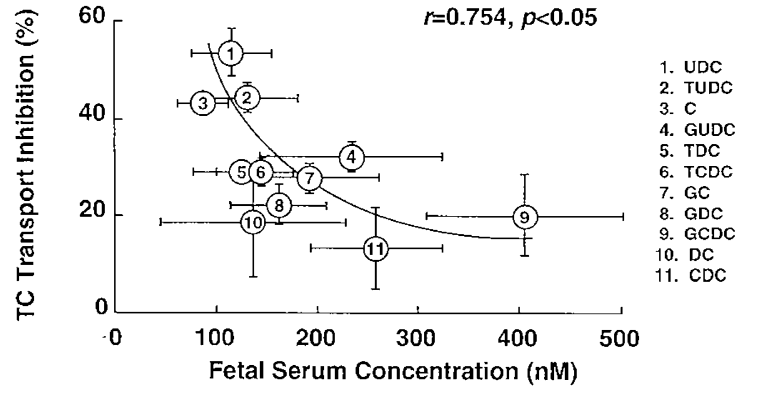

Figure 4. Relationship between fetal serum concentrations of bile acid species as measured by HPLC separation combined with enzymatic fluorescent quantification and their ability to inhibit taurocholate uptake by basal plasma membrane vesicles obtained from human trophoblast. The composition of the intravesicular medium was as follows: $250 \mathrm{mM}$ sucrose, $100 \mathrm{mM} \mathrm{KNO}_{3}, 10$ $\mathrm{mM} \mathrm{MgCl} 2,0.2 \mathrm{mM} \mathrm{CaCl}_{2}, 10 \mathrm{mM}$ Hepes/Tris, $\mathrm{pH}$ 7.40. Incubation medium composition was similar to this but contained $50 \mu \mathrm{M}\left[{ }^{14} \mathrm{C}\right]$ taurocholate and $300 \mu \mathrm{M}$ of one of the indicated bile acids. Taurocholate uptake was measured $30 \mathrm{~s}$ after incubation at $37^{\circ} \mathrm{C}$. Values are means \pm SEM from uptake experiments carried out in triplicate on at least four different placental plasma membrane vesicle preparations and from data obtained by determining concentrations in serum samples collected at term from fetuses $(n=20)$ immediately after the delivery. See Figure 3 for abbreviations.

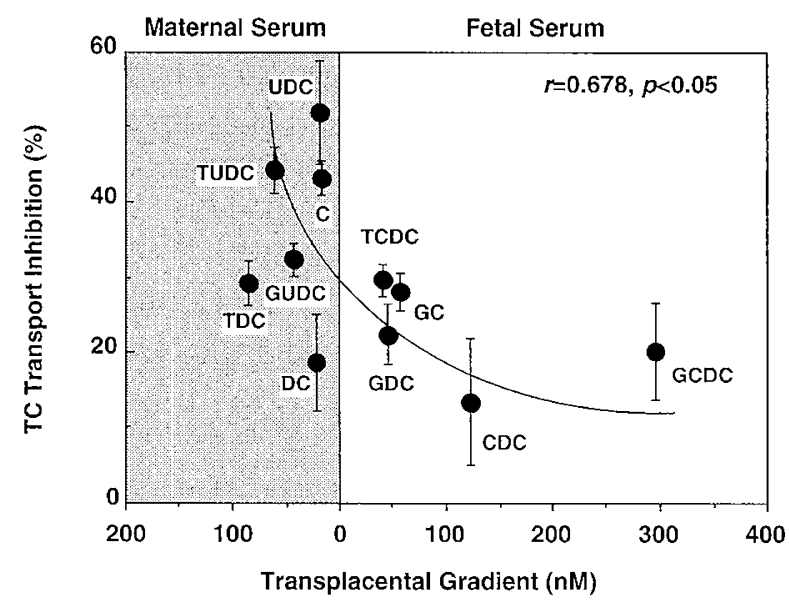

Figure 5. Relationship between transplacental gradients of bile acid species as measured by HPLC separation combined with enzymatic fluorescent quantification in fetal and maternal serum samples and their ability to inhibit taurocholate uptake by basal plasma membrane vesicles obtained from human trophoblast. The composition of the intravesicular medium was as follows: 250 $\mathrm{mM}$ sucrose, $100 \mathrm{mM} \mathrm{KNO}_{3}, 10 \mathrm{mM} \mathrm{MgCl}, 0.2 \mathrm{mM} \mathrm{CaCl}, 10 \mathrm{mM}$ Hepes/Tris, pH 7.40. Incubation medium composition was similar to this but contained $50 \mu \mathrm{M}\left[{ }^{14} \mathrm{C}\right]$ taurocholate and $300 \mu \mathrm{M}$ of one of the indicated bile acids. Taurocholate uptake was measured $30 \mathrm{~s}$ after incubation at $37^{\circ} \mathrm{C}$. Values are means \pm SEM from uptake experiments carried out in triplicate on at least four different placental plasma membrane vesicle preparations and from data obtained by determining concentrations in paired serum samples collected at term from mothers and fetuses $(n=20)$ immediately before and after the delivery, respectively. See Figure 3 for abbreviations.

are depicted in Figures 4 and 5, both linear and nonlinear correlations were statistically significant in both cases (data not shown). Owing to the considerable variability of individual values for serum concentrations of different bile acid species and to the complexity of the processes involved in establishing the net gradient of these compound across the placenta, an elucidation of the actual mathematical nature of this correlation would be out of the scope of this study. By contrast, the main contribution of this report is the finding of the existence of such a relationship, which clearly points to an important role of the fetal-facing membrane of the trophoblast in the control of the net transplacental flux for the different molecular species of bile acids.

\section{DISCUSSION}

The intrauterine life of the human fetus depends on different and complex functions performed by the placenta. Among these functions, bidirectional transfer provides the substrates required for fetal nutrition and prevents the accumulation of potentially toxic metabolites in the fetal compartment. This flux of substances across the placental barrier occurs both by simple diffusion and by carrier-mediated transport processes. The results included in this report support the notion that cholephilic organic anions need to be transferred by specific carrier owing to the low permeability of the lipid bilayers to these compounds (3).

Previous studies have shown the existence of a significant correlation between the magnitude of the accumulation of both bilirubin and bile acids in the neonate (37). This may partially reflect the deficiencies in adequate conjugation but also the immaturity in sinusoidal and/or canalicular transport processes. However, during intrauterine life, the accumulation of bilirubin at the fetal side of the compartments separated by the placenta must be due to the result of both bilirubin production by the fetus and its limitation to cross the trophoblast. Our investigation concerning the relationship of these two aspects of placental excretory function reveals that although both bile acids and bilirubin probably interact with the anion-exchanger carrier located in the basal membrane of the trophoblast, the magnitude of their accumulation in the fetus does not seem to be directly related. Therefore, additional and independent processes may account for different overall transfer of these compounds across the placenta and/or metabolism by both the mother and the fetus.

Although the human fetus is capable of bile acid synthesis, the rate of this metabolic pathway and pool size are lower than in the adult $(38-40)$. However, the results obtained in the present work confirm previous findings by other groups on the relative fetal and, to a lesser extent, also maternal hypercholanemia in uncomplicated pregnancies. Moreover, in spite of the large variability in the bile acid profiles of both fetal and maternal blood (1), these studies indicate that, in agreement with previous reports by other authors $(41,42)$, in normal term infants at birth, bile acid profiles for major bile acid species are generally different from those of their mothers. With regard to the ratio of two major primary bile acid families in the fetal and adult bile acid pool, the mean value for the cholic acid:CDC ratio was 0.61 in the fetuses and 1.79 in their mothers. This has been interpreted (41) as being due to the immaturity of the $12 \alpha$-hydroxylase enzyme system in the fetal liver (43). Our results suggest that a lower ability of $\mathrm{CDC}$, compared with the cholic acid family, to interact with the carrier responsible for entry into the trophoblast may also be involved in the differential accumulation of cholic acid versus $\mathrm{CDC}$ in the fetal compartment. This difference in the ability to cross the placenta may additionally contribute to increasing the cholic acid:CDC 
ratio in the mother. These findings are consistent with those obtained in other species, such as the sheep, where the transplacental transfer of $\mathrm{CDC}$ has been reported to occur very slowly (44).

The state of fetal hypercholanemia reflects not only an early development of the enzyme cquipment needed by the fetal liver to synthesize bile acids, but also the immaturity of the enterohepatic circulation. Hepatic insufficiency with respect to bile acid transport in the fetal state (45) is compensated for by the placental transfer of these compounds toward the mother. The fact that serum bile acid concentrations are markedly increased shortly after birth $(37,46,47)$ supports the idea that the placenta plays a key role in the control of fetal cholanemia by compensating the immaturity of biliary function in the fetal liver. The available experimental data are also consistent with the existence of this "biliary-like" placental function in other mammalian species $(44,48,49)$. Therefore, a normal developmental condition after loss of the placental pathway for bile acid excretion is the so-called state of "physiologic cholestasis," which is overcome by the newborn during the first year of life $(37,50,51)$.

The occasionally severe increase in maternal serum bile acid concentrations has been associated with the appearance of unexplained pruritus during the second half of pregnancy, in previously healthy women. Pruritus vanishes rapidly after delivery and alterations in laboratory data, characteristic of cholestasis, return to normal values in the subsequent days or weeks $(52,53)$. In these mothers, no statistically significant associations have been found between the magnitude of their hypercholanemia and maternal age, the number of previous pregnancies, previous use of oral contraceptives, fetal maturity, or the presence of pruritus in previous pregnancies (54). Taking into account the importance of the excretory function of the placenta, an interesting question arises as to whether this particular condition, which is observed during certain pregnancies and is usually classified as obstetric cholestasis, may be accounted for, at least in part, by an alteration in the normal fetal to maternal bile acid exchange. This can be important as far as both qualitative and quantitative transfer of fetal-made bile acids are concerned. For instance, the impairment in this placental function might allow a spillover into the maternal blood of greater amounts of typically fetal bile acid species which are known to be potentially cholestatic, such as $3 \beta$ hydroxy-5-cholenoate (55).

Acknowledgments. The authors thank the members of the Gynecology and Obstetrics Department of the "Virgen de la Vega" Hospital, Salamanca, Spain, for their help in the processing of human samples. The secretarial work of M. Isabel Hernandez and the technical assistance of M. Carmen Gonzalez are gratefully acknowledged. Thanks are also due to Nicholas Skinner for revision of the manuscript.

\section{REFERENCES}

1. Colombo C, Roda A, Roda E, Buscaglia M, Dell'agnola CA, Filippetti P, Ronchi M, Sereni F 1985 Correlation between fetal and maternal scrum bile acid concentrations. Pediatr Res 19:227-231
2. Watkins JB 1983 Placental transport: Bilc ació conjugation and sulfation in the fetus. J Pediatr Gastroenterol Nutr 2:365-373

3. Cabral DJ, Small DM, Lilly HS, Hamilton JA 1987 Transbilayer movement of bile acids in model membrancs. Biochemistry 26:1801-1804

4. Marin JJG, Serrano MA, El-Mir MY, Eleno N, Boyd CAR 1990 Bile acid transport by basal plasma membrane vesicles of human term placental trophoblast. Gastroenterology 99:1431-1438

5. Iioka H, Hisanaga H, Akada S, Shimamoto T, Yamada Y, Sakamoto Y, Moriyama IS Ichijo M 1993 Characterization of human placental activity for transport of taurocholate, using brush border (microvillous) membrane vesicles. Placenta 14:93-102

6. Dumaswala R, Setchell KDR, Moyer MS, Suchy FJ 1993 An anion exchangc mediates bilc acid transport across the placental microvillous membranc. Am J Physiol 264:G1016-G1023

7. Marin JJG, Bravo P, El-Mir MY, Serrano MA 1993 ATP-dependent bile acid transport by apical plasma membrane of human term placenta. J Hepatol 18:S41(abstr)

8. Serrano MA, Bravo P, El-Mir MY, Marin JJG 1993 Influence of hydroxylation and conjugation in cross-inhibition of bile acid transport across the human trophoblast basal membranc. Biochim Biophys Acta 1151:28-34

9. Boyer JL, Graf J, Meier PJ 1992 Hepatic transport systems regulating pHi, cell volume, and bile secretion. Annu Rev Physiol 54:415-438

10. Bravo P, El-Mir MY, Serrano MA, Boyd CAR, Marin JJG 1993 Interaction between cholephilic anions and bile acid transport across basal membrane of human trophoblast. Am J Physiol 265:G242-G250

11. Beck T 1991 Placental morphometry using a computer assisted measuring programme: Reference values for normal pregnancies at term. Gynccol Obstet 249:135-147

12. Beck T 1991 Placentone architecture as a structural basis for histometric investigation of the human placenta. In: Soma H (cd) Placenta: Basic Research For Clinical Application, Tokyo 1990, International Conference on Placenta. Karger, Basel, Switzerland, pp 46-58

13. Kelley LK, Smith CH, King BF 1983 Isolation and characterization of the basal cell membrane of human placental trophoblast. Biochim Biophys Acta 734:91-98

14. Williams LT, Jarett L, Lefkowitz RJ 1976 Adipocyte $\beta$-adrenergic receptors. Identification and subcellular localization by $\left[{ }^{3} \mathrm{H}\right]$ dihydroalprenolol binding. J Biol Chem 251:3096-3104

15. Bretaudicre JP, Spilmann T 1984 Alkaline phosphatases. Orthophosphoric monoester phosphohydrolase (alkaline optimum). In: Bergmeyer HU (ed) Methods of Enzymatic Analysis. Verlag Chemic GmbH, Weinheim, FRG, pp 75-83

16. Moss DW 1984 Acid phosphatases. Orthophosphoric monoester phosphohydrolase. In: Bergmeyer HU (ed) Methods of Enzymatic Analysis. Verlag Chemic GmbH Weinheim, FRG, pp 92-101

17. Baginski ES, Foa PP, Zak B 1974 Glucose-6-Phosphatase. In: Bergmeyer HU (ed) Methods of Enzymatic Analysis. Verlag Chemie GmbH, Weinheim, FRG, pp 876-880

18. Pennington RJ 1961 Biochemistry of dystrophic musclc. Mitochondrial succinatetetrazolium reductase and adcnosine triphosphatase. Biochem J 80:649-654

19. El-Mir MY, Eleno N, Serrano MA, Bravo P, Marin JJG 1991 Bicarbonate-induced activation of taurocholate transport across the basal plasma membrane of the human term trophoblast. Am J Physiol 260:G887-G894

20. Markwell MAK, Hats SM, Bicber LL, Tolbert NE 1978 A modification of the Lowry procedure to simplify protein determination in membranc and lipoprotcin samples. Anal Biochem 87:206-210

21. Hopfer U, Nelson K, Perroto J, Isselbacher KJ 1973 Glucose transport in isolated brush-border membranes from rat small intestine. J Biol Chem 248:25-32

22. Setchell KDR, Worthington JA 1982 Rapid method for the quantitative extraction of bile acids and their conjugates from serum using commercially available reverse phase octadecylsilane bonded silica cartridges. Clin Chim Acta 125:135-144

23. Talalay P 1960 Enzymatic analysis of steroid hormones. Methods Biochem Anal $8: 119-143$

24. Mashige U, Imai $\mathrm{K}$, Osuga TA 1976 Simple and sensitive assay of total serum bile acids. Clin Chim Acta 70:79-86

25. Rossi SS, Converse JL, Hofmann AF 1987 High pressure liquid chromatographic analysis of conjugated bile acids in human bile: Simultancous resolution of sulfated and unsulfated lithocholyl amidates and the common conjugated bilc acids. J Lipic Res 28:589-595

26. Monte MJ, Badia MD, Palomero F, El-Mir MY, Alonso JR, Marin JJG 1993 Effects of selective zonal injury on bile acid-induced bile flow in the isolated rat liver. Am J Physiol 264:G1103-G1111

27. Malloy HT, Evelyn KA 1937 The determination of bilirubin with the photoelectric colorimeter. J Biol Chem 199:480-490

28. Trinder P 1969 Determination of glucose in blood using glucose oxidase with an alternative oxygen acceptor. Ann Clin Biochem 6:24-34

29. Prencipe L, Brenna S, Sordi CE 1983 Automated scquential urea and glucose assay in one cuvet. Clin Chem 29:1315-1316

30. Siedel J, Hagele EO, Ziegenhorn J, Wahlefeld AW 1983 Reagent for the enzymatic determination of scrum total cholesterol with improved lipolytic efficiency. Clin Chem 29:1075-1080

31. Nagele U, Hägcle EO, Saucr G, Wiedeman E, Lchmann P, Wahlcfeld AW, Gruber W 1984 Reagent for the enzymatic determination of serum total triglycerides with improved lipolytic efficiency. J Clin Chem Clin Biochem 22:165-174

32. Karmen A 1955 A note on the spectrophotometric assay of glutamic oxalacetic transaminase in human blood serum. J Clin Invest 34:131-135

33. Wroblewski F, LaDue JS 1956 Serum glutamic-pyruvic transaminase in cardiac and hepatic disease. Proc Soc Exp Biol Med 91:569-571

34. Persijn JP, Vander Slik W 1976 A new method for the determination of $\gamma$-glutamilyltransferase in serum. J Clin Chem Clin Biochem 14:421-424 
35. Gutmann I, Wahlefeld AW $1974 \mathrm{~L}-(+)$-Lactate. Determination with lactate dehydrogenase and NAD. In: Bergmeyer HU (ed) Methods of Enzymatic Analysis. Verlag Chemic GmbH, Weinheim, FRG, pp 1464-1468

36. Bessey O, Lowry OH, Brock MJ 1946 Mcthod for the determination of alkaline phosphatase with five cubic millimeters of serum. J Biol Chem 164:321-329

37. Barnes S, Berkowitz G, Hirschowitz BI, Wirtschaltor D, Cassady G 1981 Postnata physiologic hypercholemia in both premature and full term infants. $J$ Clin Inves 68:775-782

38. Watkins JB, Ingall D, Szczepanik P, Klcin PD, Lester R 1973 Bilc salt metabolism in the newborn. N Engl J Mcd 288:431-434

39. Watkins JB, Szczepanik P, Gould JB, Klein PD, Lester R 1975 Bilc salt metabolism in the human premature infant. Gastroenterology 69:706-713

40. Nakagawa M, Setchell KDR 1990 Bile acid metabolism in early life: Studics in amniotic fluid. J Lipid Res 31:1089-1098

41. Colombo C, Zuliani G, Ronchi M, Breidenstein J, Setchell KDR 1987 Biliary bilc acid composition of the human fetus in early gestation. Pediatr Res 21:197-200

42. Laatikainen $T 1977$ Feto-maternal reiationships of serum bile acids in uncomplicated pregnancy. Scand J Clin Lab Invest 37:605-608

43. Gustafsson J 1985 Bile acid synthesis during development. Mitochondrial $12 \alpha-$ hydroxylation in human fetal liver. J Clin Invest 75:604-607

44. Scwell RB, Hardy KJ, Smallwood RA, Hoffman NE 1982 Fetal bile salt metabolism: placental transfer of dihydroxy bile salts in sheep. Am J Physiol 6:G172-G175

45. Bath R, Bernstein MS, Anderson RJ, Vidyasagar D, Evans MA 1985 Uptake of taurocholate by freshly isolated hepatocytes from fetal and newborn rabbits. Biol Neonate 47:99-106

46. Barbara L, Lazzari R, Roda A, Aldini R, Festi D, Sama C, Morselli AM, Collina A Bazzoli F, Mazzella G, Roda E 1980 Scrum bile acids in newborns and children. Pediatr Res 14:1222-1225
47. Heikura S, Simila S, Finni K, Maentausta O, Janne O 1980 Cholic and chenodeoxycholic acid concentrations in serum during infancy and childhood. Acta Paediatr Scand 69:659-664

48. Hardy KJ, Hoffman NE, Mihaly G, Sewell RB, Smallwood RA 1980 Bile acid metabolism in the fetal sheep: Perinatal changes in the bile acid pool. J Physiol 309:1-11

49. Jackson BT, Smallwood RA, Piasecki GJ, Brown AS, Rauschecker HFJ, Lester R 1971 Fetal bilc salt metabolism. The metabolism of sodium cholatc in the fetal dog. $\mathrm{J}$ Clin Invest 50:1286-1294

50. Suchy FJ, Balistreri WF, Heubi JE, Searchy JE, Levin RS 1981 Physiologic cholestasis: Elevation of the primary serum bile acid concentrations in normal infants. Gastroenterology 80:1037-1041

51. Tikanoja T, Tikanoja S, Simell O 1981 Plasma conjugated cholic acid in premature and term newborns and young infants. Acta Paediatr Scand 70:491-495

52. Svanborg A 1954 A study of recurrent jaundice in pregnancy. Acta Obstet Gynecol Scand 33:434-444

53. Rcyes H 1982 The enigma of intrahepatic cholestasis of pregnancy: Lessons from Chile. Hepatology 2:87-96

54. Lunzer M, Barnes P, Byth K, O'Halloran M 1986 Serum bile acid concentrations during pregnancy and their relationship to obstetric cholestasis. Gastroenterology 91:825-829

55. Shoda J, Osuga T, Matsuura K, Mahara R, Tohma M, Tanaka N, Matsuzaki Y, Miyazaki H 1989 Concurrent occurrence of $3 \beta, 12 \alpha$-dihydroxy-5-cholenoic acid associated with $3 \beta$-hydroxy-5-cholenoic acid and their preferential urinary excretion in liver diseases. J Lipid Res 30:1233-1242 